\title{
Üstbiliş Eğitiminin Uzaktan Eğitim Öğrencilerinin Üstbilişsel Farkındalık Seviyelerine Etkisinin İncelenmesi*
}

\author{
Melike Aydemir** \\ Makale Geliş Tarihi: 26/10/2018 \\ Makale Kabul Tarihi: 23/11/2018 \\ DOI: $10.35675 /$ befdergi.481239
}

$\ddot{O} z$

Araştırmanın amacı üstbiliş eğitimi alan ve almayan uzaktan eğitim öğrencilerinin üstbiliş seviyelerinin incelenmesidir. Uzaktan ĕgitim ögrrencilerinin üstbilişsel farkindalık seviyelerinin tespiti için statik grup karşılaştırmalı desen uygulanmıştır. Araştırmanın örneklemini Atatürk Üniversitesi Açıkögrretim Fakültesi 1. sinıf ögrencilerinden 307 kişi oluşturmaktadır. Üstbiliş eğitimi için eğitsel yazılım geliştirilmişstir. Eğitsel yazılım ile üstbiliş, üstbilişin özellikleri ve önemi, üstbiliş bileşenleri, üstbilişs stratejileri ve örnekleri Öğretim Yönetim Sistemi (ÖYS) üzerinden öğrencilere aktarllmıştır. Çalışmada veri toplama aracı olarak üstbiliş eğitiminin ögrencilerin üstbilişsel farkındalık seviyelerine etkisini incelemek için "Bilişötesi Farkındalık Envanteri” kullanılmıştır. Veriler bağımsız t-testi ile analiz edilmiştir. Çalışma sonucunda üstbiliş eğitiminin uzaktan eğitim ögrencilerinin üstbilişsel farkındalık seviyeleri üzerinde etkili olduğu görülmüştür.

Anahtar Kelimeler: Uzaktan eğitim, üstbiliş, üstbiliş eğitimi, üstbilişsel farkındalık seviyesi

\section{Investigation the Effect of Metacognition Training on Distance Education Students' Metacognitive Awareness Levels}

\begin{abstract}
The aim of this study was to examine the metacognitive awareness levels of distance education students who receive and do not receive the metacognition training. Static group comparison design was used to determine metacognitive awareness levels of distance education students who did or did not receive metacognition teaching. The sample of this research consists of 307 first grade students of Ataturk University Open Education Faculty. Metacognition, characteristics and importance of metacognition, metacognitive components, metacognitive strategies and examples are explained through multimedia elements in the educational software at Learning Management System (LMS). In this study, "Metacognitive Awareness Inventory (MAI)" was used to examine the effect of metacognition teaching on metacognitive awareness levels of distance education students. Data were analyzed by independent t-test. There was a significant difference in metacognition awareness levels between students who have metacognition teaching and don't receive metacognition teaching.
\end{abstract}

Keywords: Distance education, metacognition, metacognition training, metacognitive awareness level

\footnotetext{
"Çalışmanın ilk hali "27. Uluslararası Eğitim Bilimleri Kongresi”nde bildiri olarak sunulmuştur.

${ }^{* *}$ Atatürk Üniversitesi, Açıöŏgretim Fakültesi, Büro Hizmetleri ve Sekreterlik, Erzurum, Türkiye. ORCID: 0000-0002-5899-2175

Kaynak Gösterme: Aydemir, M. (2019). Üstbiliş eğitiminin uzaktan eğitim öğrencilerinin üstbilişsel farkındalık seviyelerine etkisinin incelenmesi. Bayburt Eğitim Fakültesi Dergisi, 14(27), 71-86. https://doi.org/10.35675/befdergi.481239
} 


\section{Giriş}

İlk kez Flavell (1979) tarafından açıklanan üstbiliş eğitim alanındaki çalışmalarda sürekli gündeme gelmiş ve kullanılmıştır. Üstbiliş denince düşünme, öğrenme, bilme ve kontrol kelimeleri akla gelmektedir. "Düşünme hakkında düşünme", "düşünme hakkında öğrenme", "bilme hakkında bilme", "bilme hakkında düşünme" ve "öğrenmenin kontrolü" şeklinde bu kelimelerin kombinasyonları yapılarak üstbiliş genel olarak tanımlanmaktadır (Blakey ve Spence, 1990; Papaleontiou-Louca, 2003).

Üstbiliş iki alt boyuttan oluşmaktadır. Bunlar; biliş bilgisi ve biliş düzenlemesidir. $\mathrm{Bu}$ iki alt boyutun da alt bileşenleri bulunmaktadır. Biliş bilgisi ise açıklayıcı, prosedürel ve durumsal bilgiden oluşmaktadır. Biliş düzenlemesi ise bilgiyi yönetme, değerlendirme, hata ayıklama, izleme ve değerlendirmeden oluşmaktadır (Schraw ve Dennison, 1994). Şekil 1'de üstbilişin yapısı gösterilmektedir.

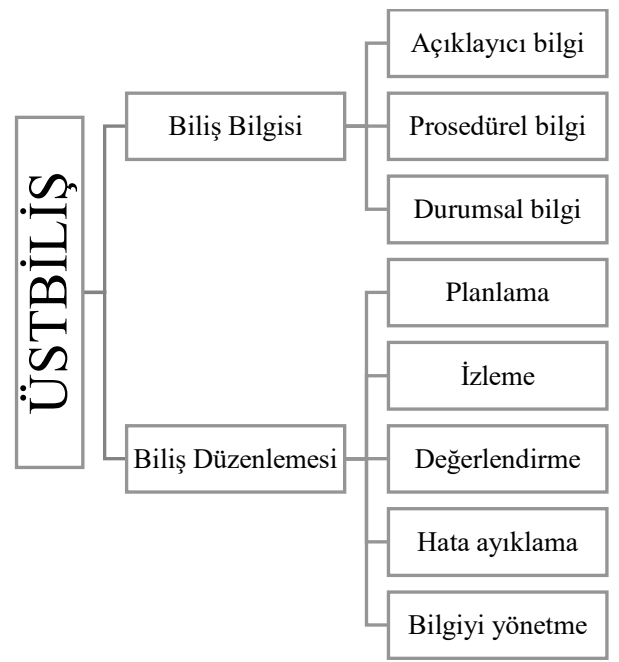

Şekil 1. Üstbilişin yapısı (Schraw ve Dennison, 1994)

Biliş bilgisi: Bireylerin kendi bilişsel süreçleri hakkındaki bilgisidir (Flavell, 1979). Açıklayıcı, prosedürel ve durumsal bilgiden oluşmaktadır. Açıklayıcı bilgi; bilişsel süreçlere yönelik ne bilgisini içermektedir. Prosedürel bilgi; bilişsel süreçlerin nasıl gerçekleştiğine yönelik bilgiyi içermektedir. Durumsal bilgi ise bilişsel süreçlerin hangi koşullarda ve niçin oluştuğuna yönelik bilgileri içermektedir (Akın, Abacı ve Çetin, 2007; Kana, 2015; Schraw ve Dennison, 1994; Thomas ve McRobbie, 2001).

Biliş düzenlemesi: Bireyin kendi bilişsel süreçlerine yönelik denetleme, izleme, değiştirme ve değerlendirme gibi zihinsel eylemleri içerir. Biliş düzenlemesi 5 boyuttan oluşmaktadır. Planlama zihinsel süreçlere yönelik uygun strateji seçimidir. İzleme, bireyin kendi bilişsel süreçlerdeki performansını analiz etmesidir. Değerlendirme, bireyin öğrenme süreci sonunda kendi öğrenmesini 
değerlendirmesidir. Hata ayıklama bireyin öğrenme sürecindeki hatalarına yönelik düzeltme yapmasıdır. Bilgiyi yönetme ise bireyin zihinsel süreçlerinde bilgiyi daha verimli işlemesidir (Bağçeci, Döş ve Sarıca, 2011; Schraw ve Dennison, 1994).

Üstbilişe sahip bireyler öğrenme ve anlamanın farkında olarak bu süreçleri kontrol etmekte ve düzenlemektedirler (Brown, 1987). Böylece üstbilişe sahip bireyler öğrendiklerine ve zihinsel süreçlerine dikkat etmekte, bu süreçleri anlamakta, uygulamakta ve düzenlemektedirler (Hartman, 1998). Yapılan çalışmalarda görülmektedir ki üstbiliş eğitimi ile bireylerin kendi zihinsel ve öğrenme süreçlerinin nasıl işlediği, denetleyebileceği ve düzenleyebileceğine yönelik bilgi ve beceriler kazandırılmaktadır (Aydemir, 2014; Pintrich, Wolters ve Baxter, 2000; Schraw, Wise ve Roos, 2000; Veenman, Elshout ve Busato, 1994). Üstbiliş eğitimi ile bireylerin üstbilişlerinin aktifleştirilmesi ve geliştirilmesi amaçlanmaktadır (Öztürk, 2016). Böylece bireyler öğrenmelerini de geliştirebilmektedirler (Veenman, Elshout ve Busato, 1994).

Uzaktan eğitim daha çok bireysel öğrenmeye yatkın öğrenme ortamlarını ve süreçlerini içermektedir. Öğrenen bu ortamlarda kendi öğrenmesini gerçekleştirmektedir. Üstbilişe sahip bireyler de kendi öğrenme süreçlerinin fakında olmakta, denetleyebilmekte ve düzenleyebilmektedirler (Joseph, 2009). Bu açıdan uzaktan eğitimde üstbiliş oldukça önemli bir role sahiptir (Azevedo, 2005). Üstbiliş eğitimine uzaktan eğitim öğrencilerinin ihtiyaç duyduğu (Tok, Özgan ve Döş, 2010; Zahedi ve Dorrimanesh, 2008) ve bu yüzden bu ortamlarda üstbiliş eğitimine yer verilmesi gerektiğine (Aydemir, 2014) yönelik dikkat çekilmelidir.

Uzaktan eğitimde üstbiliş eğitimi yapan çalışmalar incelendiğinde; üstbilişsel bilgi ve stratejilerin eğitsel yazılımlar aracılığıyla öğrencilere aktarıldığı görülmektedir (Gama, 2001; Howard, McGee, Hong ve Shia, 2000; Singh, 2009; Vovides, 2005). Bu çalışmalardaki sonuçlara göre üstbilişsel eğitiminin uzaktan eğitimde kullanımının etkili olabileceği görülmüştür. Ayrıca üstbilişin geliştirilmesinde öğretmenin rolü oldukça önemlidir. Öğretmen öğrencilerin üstbilişini geliştirmesi yönünde etkileşimde bulunmalıdır (Curwen, Miller, White-Smith ve Calfee, 2010; Mayer, 1987; Öztürk, 2016). Ayrıca uzaktan eğitimde öğrenenler genelde bireysel öğrendikleri için üstbilişlerini geliştirmeleri bakımından desteklenmesi gerekmektedir. Bunun için bu çalışmada üstbiliş eğitimine yönelik yazılım geliştirilmiş ve öğrencilere sunulmuştur.

\section{Araştırmanın Amacı ve Soruları}

Araştırmanın amacı üstbiliş eğitimi alan ve almayan uzaktan eğitim öğrencilerinin üstbilişsel farkındalık seviyelerinin incelenmesidir. Bu amaç doğrultusunda aşağıdaki araştırma soruların incelenmiştir.

Üstbiliş eğitimi alan ve almayan uzaktan eğitim öğrencilerinin; 
1. Üstbilişsel farkındalık seviyeleri bakımından anlamlı bir farklılık var mıdır?

2. Biliş bilgisi seviyesinde anlamlı bir farklılık var mıdır?

a. Açıklayıcı bilgi seviyesinde anlamlı bir farklılık var mıdır?

b. Prosedürel bilgi seviyesinde anlamlı bir farklılık var midır?

c. Durumsal bilgi seviyesinde anlamlı bir farklılık var midır?

3. Biliş düzenlemesi seviyesinde anlamlı bir farklılık var mıdır?

a. Planlama seviyesinde anlamlı bir farklılık var mıdır?

b. İzleme seviyesinde anlamlı bir farklılık var mıdır?

c. Değerlendirme seviyesinde anlamlı bir farklılık var mıdır?

d. Hata ayıklama seviyesinde anlamlı bir farklılık var mıdır?

e. Bilgiyi yönetme seviyesinde anlamlı bir farklılık var mıdır?

\section{Yöntem}

\section{Araştırma Deseni}

Üstbiliş eğitimi alan ve almayan uzaktan eğitim öğrencilerinin üstbilişsel farkındalık seviyelerinin tespiti için statik grup karşılaştırmalı desen uygulanmıştır. Statik grup karşılaştırmalı desende iki grubun son ölçümleri karşılaştırılır. Bir grupta uygulama yapılırken bir diğer gruba uygulama yapılmamaktadır. Uygulama sonunda gruplar karşılaştırılmaktadır. Gruplara atamalar seçkisiz değildir, hazır gruplar söz konusudur, bu gruplardan biri kontrol diğeri ise deney grubu olarak tespit edilir (Büyüköztürk, Kılıç Çakmak, Akgün, Karadeniz ve Demirel, 2008). Bu araştırmada üstbiliş eğitimi alan ve almayan iki grup belirlenmiştir. Süreç sonunda bu iki grubun üstbilişsel farkındalık seviyelerini tespit eden ölçek puanları karşılaştırılmıştır.

\section{Örneklem}

Araştırmanın örneklemini Atatürk Üniversitesi Açıköğretim Fakültesi 1. Sınıf farklı bölümlerde okuyan öğrenciler oluşturmaktadır. Örneklem kolay ulaşılabilir örneklem yöntemi ile seçilmiş 307 kişiden oluşmaktadır. Üstbiliş eğitim materyalini kullanan ve kullanmayan öğrencilerin tercih edilmesinden dolayı kolay ulaşılabilir birimlerden seçilmiştir. Bu yöntemdeki temel amaç, zaman ve iş gücü kaybını önlemektir (Büyüköztürk vd., 2008; Fraenkel ve Wallen, 2006). Çalışmadaki örnekleme yönelik genel bilgiler Tablo 1'de sunulmuştur. 
Tablo 1.

Örnekleme Yönelik Bilgiler

\begin{tabular}{llcc}
\hline \multirow{2}{*}{ Bilgiler } & Yanıtlar & Öğrenci sayısı & \\
\cline { 3 - 4 } & & $\mathbf{n}$ & $\boldsymbol{\%}$ \\
\hline Cinsiyet & Erkek & 108 & 35.18 \\
& Kadın & 199 & 64.82 \\
\hline Yaş Aralığı & 20 yaş öncesi & 30 & 9.77 \\
& $20-30$ & 118 & 38.44 \\
& $31-40$ & 79 & 25.73 \\
& $41-50$ & 48 & 15.64 \\
& $51-60$ & 32 & 10.42 \\
\hline Üstbiliş materyal kullanımı & Evet & 153 & 49.84 \\
& Hayır & 154 & 50.16 \\
\hline
\end{tabular}

Tablo 1 incelendiğinde öğrencilerin çoğunluğu bayanlardan oluşmaktadır (\%64.82). Öğrencilerin büyük çoğunluğu 20-30 yaş aralığına sahiptir. Bunu sırasıyla 30-40 yaş aralığı (\%25.73), 40-50 yaş aralığ1 (\%15.64), 50-60 yaş aralığ $(\% 10.42)$ ve 20 yaş öncesi (\%9.72) takip etmektedir. Üstbiliş materyalini kullanarak eğitim alanlar $\% 49.84$ iken eğitim almayanlar ise $\% 50.16$ 'dır.

\section{Üstbilişsel Eğitsel Yazılımı}

Geliştirilen eğitsel yazılımda üstbiliş, üstbilişin özellikleri ve önemi, üstbiliş bileşenleri, üstbiliş stratejileri ve örnekleri aktarılmıştır. Yazılımda uzaktan eğitim öğrencilerine üstbiliş temelinde bilgiler verilerek kendi öğrenmelerinin ve bilişlerinin farkına varması amaçlanmıştır. Üstbiliş eğitsel yazılımı ÖYS üzerinden öğrencilere sunulmuştur. Üstbilişsel Eğitsel Yazılım öğrencilerin ÖYS'deki ana ekranında yer almıştır. Yazılımı kullandıktan sonra anket sorularına cevap vermeleri istenmiştir. Yazılımda toplamda iki-üç dakikadan oluşan dört adet eğitsel video, kavram ağ1, değerlendirme soruları yer almaktadır. Yazılımda altı bölüm bulunmaktadır. İlk bölümde öğrencilere bu eğitsel yazılım kullanımı sonrasında edinecekleri öğrenme çıktılarından bahsedilmektedir. İkinci bölümde üstbiliş hakkında bilgiler verilmektedir. Üçüncü bölümde üstbilişsel stratejiler anlatılmaktadır. Dördüncü bölümde üstbilişsel etkinlikler anlatılmaktadır. Beşinci bölümde değerlendirme soruları bulunmaktadır. Altıncı bölümde ise eğitsel yazılımın kullanımı hakkında bilgi verilmektedir.

Üstbiliş eğitim materyalinde çoklu ortam tasarım ilkeleri kullanılmıştır (Mayer, 2009). Kullanılan ilkelerin kullanım amaçları aşağıda açıklanmıştır.

Çoklu ortam ilkesi: Uzaktan eğitim sürecinde de öğrenciler bağımsız öğrenme gerçekleştirdikleri için materyallerin birden fazla kanala hitap etmesi öğrenme bakımından önemlidir. Eğitsel yazılımda sadece ses, metin, görsel (tablo, kavram ă̆ı, 
resim) kullanmak yerine bu öğeler uygun bir şekilde her bir bölümde aynı oranlarda kullanılmıştır.

Konumsal yakınlık ilkesi: Geliştirilen eğitsel yazılımda kullanılan ilgili görsel ve metinler birbirine yakın bir şekilde yer almıştır. İlgili görselin açıklaması hemen yanında verilmiş ve birbirleri ile ilgili olduğu mesajı verilmiştir.

Zamansal yakınlık ilkesi: $\mathrm{Bu}$ ilke kapsamında geliştirilen eğitsel yazılımda ekrana gelen resimlerle ilgili yazılar veya uygun seslendirmeler aynı anda verilmiştir. Böylece yazılımı kullananlar konuyla ilgili iki öğenin bağlantısını kurabilmişlerdir.

Tutarlılık ilkesi: Eğitsel yazılımda kullanılan öğelerin konu ve kapsam ile tutarlı olmasına dikkat edilmiştir. Yazılımdaki görseller ve metinler konu içeriğine uygun olarak seçilmiş ve ilgili yerlerde kullanılmıştır.

Duyu biçimi ilkesi: Animasyon ve seslendirilmiş anlatım, animasyon ve düz yazıdan oluşmuş bir anlatımdan daha iyi öğrenmeyi sağlamaktadır. Bu amaçla geliştirilen yazılımda animasyonlar seslendirilmiştir.

Gereksizlik ilkesi: Gereksiz yere öğelerin kullanımı öğrencilerin anlamasını ve öğrenmesini zorlaştırdığında eğitsel yazılımda ses, yazı ve görsel kullanımının birlikte olmasından ziyade iki öğenin olmasına dikkat edilmiştir.

Kişiselleştirme ilkesi: Eğitsel yazılımda öğrenci seviyesi göz önüne alınarak anlatımlarda ve tasarımda akademik dil yerine öğrencilerin konu kapsamında anlayabileceği günlük dil kullanılmaya çalışılmıştır.

Dikkat çekme ilkesi: $\mathrm{Bu}$ ilke ile eğitsel yazılımdaki öğelerin dikkat çekici olmasına özen gösterilmiştir. Eğitsel yazılımın başlangıcında, ilerleyen bölümlerde ve sonunda dikkat çekici öğelere yer verilmiştir.

Parçalama -bölme ilkesi: $\mathrm{Bu}$ kapsamda eğitim yazılımında konular anlamlı şekilde bölümlendirilmiş basitten karmaşığa doğru gidilecek şekilde aktarılmıştır.

Ses ilkesi: Bu kapsamda eğitsel yazılımdaki tüm seslendirmeler kişiler tarafından gerçekleştirilmiştir.

Görüntü ilkesi: $\mathrm{Bu}$ kapsamda konu anlatımında anlatıcının görüntüsü kullanılmamıştır.

Ön alıştırma: $\mathrm{Bu}$ ilke temelinde eğitsel yazılımda her konunun başlangıcında kavram ağı yerleştirilmiştir. Böylece öğrenci konuya başlamadan ne öğreneceğinden haberdar olmuştur.

\section{Veri Toplama Aracı ve Süreci}

Çalışmada, üstbiliş eğitiminin öğrencilerin üstbiliş seviyelerine olan etkisini incelemek için Schraw ve Dennison (1994) tarafından geliştirilen "Metacognitive 
Awareness Inventory-MAI" ölçeğin Akın, Abacı ve Çetin (2007) tarafından Türkçe uyarlaması hazırlanan "Bilişötesi Farkındalık Envanteri" kullanılmıştır. Bu ölçek yetişkinler için geliştirilmiştir. Ölçekte üstbilişsel farkındalık seviyesi iki ana boyuttan oluşmaktadır. Bunlar; biliş bilgisi ve biliş düzenlemesidir. Biliş bilgisi seviyesi ise açıklayıcı bilgi, prosedürel bilgi ve durumsal bilgi boyutlarından oluşmaktadır. Biliş düzenlemesi seviyesi ise planlama, izleme, değerlendirme, hata ayıklama ve bilgiyi yönetme boyutlarından oluşmaktadır. Ölçek, (5) her zaman, (4) genellikle, (3) sık sık, (2) nadiren ve (1) hiçbir zaman şeklinde 5'li Likert tipi derecelendirmeye sahiptir. Schraw ve Dennison (1994) bu ölçeğin faktörler arasındaki ilişkiyi $r=.54$ ve güvenirliğini .90 olarak hesaplanmıştır. Akın ve diğerleri (2007) Türkçe'ye uyarladıkları bu ölçeğe geçerlik güvenilirlik analizi uygulamış güvenilirlik katsayısını .95 olarak hesaplanmıştır. Ayrıca iki ölçek arasında korelasyon olduğunu tespit etmişlerdir. Bu araştırmada bu ölçeğin Cronbach Alfa güvenilirlik katsayısı .91 olarak hesaplanmıştır.

Ölçek ÖYS üzerinden öğrencilere sunulmuştur. Üstbiliş eğitimi alan öğrenciler ölçeği üstbiliş eğitsel yazılımı kullandıktan sonra doldurmuşlardır. Eğitim almayan öğrenciler ise istedikleri zaman ölçeği doldurmuşlardır.

\section{Veri Analizi}

Çalışmada araştırma soruları göz önünde bulundurularak toplanan veriler analiz edilmiştir. Elde edilen veriler üzerinde ortalama, yüzde, standart sapma ve bağımsız t-testi gibi veri analiz işlemleri yapılmıştır. Veriler üzerinde normallik ve homojenlik testleri uygulanarak parametrik testlerin varsayımlarının karşılanıp karşılanmadığı belirlenmiştir. Varsayımlar sağlandığı için t-testi ile analizler gerçekleştirilmiştir. Çalışmada tüm istatistiki testler için anlamlılık düzeyi .05 olarak belirlenmiştir.

\section{Bulgular ve Yorum}

\section{Uzaktan Eğitim Öğrencilerinin Üstbilişsel Farkındalık Seviyeleri}

Üstbiliş eğitimi alan ve almayan uzaktan eğitim öğrencilerinin üstbilişsel farkındalık seviyelerinin farklılaşıp farklılaşmadığı tespit edilmiştir. Bunun için bağımsız t-testi kullanılarak bulgular oluşturulmuştur. Elde edilen ortalamalar ve t-testi sonuçları Tablo 2'de gösterilmiştir.

Tablo 2 .

Uzaktan Ĕgitim Öğrencilerinin Üstbilişsel Farkındalık Seviyeleri

\begin{tabular}{lccccc}
\hline Durum & $\mathbf{N}$ & $\bar{X}$ & $\mathbf{s}$ & $\mathbf{t}$ & $\mathbf{p}$ \\
\hline Eğitimi alan öğrenciler & 153 & 3.93 & .57 & & \\
Eğitimi almayan öğrenciler & 154 & 3.71 & .69 & & .003 \\
\hline
\end{tabular}


Tablo 2 incelendiğinde üstbiliş eğitimi alan öğrencilerin seviye puanı ortalaması ile ( $\bar{X}=3.93)$ üstbiliş eğitimi almayan öğrencilerin ortalamaları $(\bar{X}=3.71)$ arasında anlamlı bir fark görülmüştür $\left(\mathrm{t}_{(306)}=2.99, \mathrm{p}<.05\right)$. Bu durumda üstbiliş eğitiminin uzaktan eğitim öğrencilerinin üstbilişsel farkındalık seviyeleri üzerinde anlamlı bir etkisinin olduğu görülmüştür.

\section{Uzaktan Eğitim Öğrencilerinin Biliş Bilgisi Seviyeleri}

Üstbiliş eğitimi alan ve almayan uzaktan eğitim öğrencilerinin biliş bilgisi seviyelerinin farklılaşıp farklılaşmadığı tespit edilmiştir. Bunun için bağımsız t-testi kullanılarak bulgular oluşturulmuştur. Elde edilen ortalamalar ve t-testi sonuçları Tablo 3'te gösterilmiştir.

Tablo 3.

Uzaktan Ĕ̈itim Öğrencilerinin Biliş Bilgisi Seviyeleri

\begin{tabular}{lccccc}
\hline Durum & $\mathbf{N}$ & $\bar{X}$ & $\mathbf{s}$ & $\mathbf{t}$ & $\mathbf{p}$ \\
\hline Eğitimi alan öğrenciler & 153 & 3.97 & .59 & & \\
Eğitimi almayan öğrenciler & 154 & 3.76 & .70 & & .006 \\
\hline
\end{tabular}

Tablo 3 incelendiğginde üstbiliş eğitimi alan öğrencilerin biliş bilgisine yönelik puan ortalaması ile ( $\bar{X}=3.97)$ üstbiliş eğitimi almayan öğrencilerin ortalamaları ( $\bar{X}$ $=3.76$ ) arasında anlamlı bir fark görülmüştür $(\mathrm{t}(306)=2.75, \mathrm{p}<.05) . \mathrm{Bu}$ durumda üstbiliş eğitiminin uzaktan eğitim öğrencilerinin biliş bilgisi seviyeleri üzerinde anlamlı bir etkisinin olduğu görülmüştür.

Öğrencilerin, biliş bilgisi seviyelerinin alt boyutları olan açıklayıcı bilgi, prosedürel bilgi ve durumsal bilgi farklılaşıp farklılaşmadığı tespit edilmiştir. Bunun için bağımsız t-testi kullanılarak bulgular oluşturulmuştur. Elde edilen ortalamalar ve t-testi sonuçları Tablo 4’te gösterilmiştir.

Tablo 4.

Uzaktan Ĕ̈itim Öğrencilerinin Açıklayıcı, Prosedürel ve Durumsal Bilgi Seviyeleri

\begin{tabular}{llcccc}
\hline $\begin{array}{l}\text { Biliş bilgisi } \\
\text { seviyesi }\end{array}$ & Durum & $\bar{X}$ & $\mathbf{s}$ & $\mathbf{t}$ & $\mathbf{p}$ \\
\hline \multirow{2}{*}{ Açıklayıcı bilgi } & Eğitimi alan öğrenciler & 4.01 & .61 & & \\
& Eğitimi almayan öğrenciler & 3.86 & .68 & 1.94 & .05 \\
\hline \multirow{2}{*}{ Prosedürel bilgi } & Eğitimi alan öğrenciler & 3.75 & .80 & & \\
& Eğitimi almayan öğrenciler & 3.52 & .87 & 2.47 & .01 \\
\hline Durumsal bilgi & Eğitimi alan öğrenciler & 4.08 & .61 & &
\end{tabular}


Eğitimi almayan öğrenciler

$3.80 \quad .79$

3.45

.01

Tablo 4 incelendiğinde üstbiliş eğitimi alan öğrencilerin açıklayıcı bilgiye yönelik puan ortalaması ile ( $\bar{X}=4.01)$ üstbiliş eğitimi almayan öğrencilerin puan ortalamaları $(\bar{X}=3.86)$ arasında anlamlı bir fark görülmemiştir $(\mathrm{t}(306)=1.94, \mathrm{p}>.05)$. Bu durumda üstbiliş eğitiminin uzaktan eğitim öğrencilerinin açıklayıcı bilgi seviyeleri üzerinde anlamlı bir etkisi olmamıştır. Prosedürel bilgi seviyeleri arasında ise üstbiliş eğitimi alan öğrencilerin seviye puanı ortalaması ile $(\bar{X}=3.75)$ üstbiliş eğitimi almayan öğrencilerin ortalamaları $(\bar{X}=3.52)$ arasında anlamlı bir fark görülmüştür $(\mathrm{t}(306)=2.47, \mathrm{p}<.05)$. Bu durumda üstbiliş eğitiminin uzaktan eğitim öğrencilerinin prosedürel bilgi seviyeleri üzerinde anlamlı bir etkisinin olduğu görülmüştür. Durumsal bilgi seviyeleri arasında üstbiliş eğitimi alan öğrencilerin seviye puanı ortalaması ile ( $\bar{X}=4.08)$ üstbiliş eğitimi almayan öğrencilerin puan ortalamaları $(\bar{X}$ $=3.80$ ) arasında anlamlı bir fark görülmüştür $(\mathrm{t}(306)=3.45, \mathrm{p}<.05)$. Bu durumda üstbiliş eğitiminin uzaktan eğitim öğrencilerinin durumsal bilgi seviyeleri üzerinde anlamlı bir etkisinin olduğu görülmüştür.

\section{Uzaktan Eğitim Öğrencilerinin Biliş Düzenlemesi Seviyeleri}

Üstbiliş eğitimi alan ve almayan uzaktan eğitim öğrencilerinin biliş düzenlemesi seviyelerinin farklılaşıp farklılaşmadığı tespit edilmiştir. Bunun için bağımsız t-testi kullanılarak bulgular oluşturulmuştur. Elde edilen ortalamalar ve t-testi sonuçları Tablo 5'te gösterilmiştir.

Tablo 5 .

Uzaktan Ĕ̆itim Öğrencilerinin Biliş Düzenlemesi Seviyeleri

\begin{tabular}{lccccc}
\hline Durum & $\mathbf{N}$ & $\bar{X}$ & $\mathbf{s}$ & $\mathbf{t}$ & $\mathbf{p}$ \\
\hline Eğitimi alan öğrenciler & 153 & 3.90 & .59 & & \\
Ĕ̆itimi almayan öğrenciler & 154 & 3.68 & .72 & & .003 \\
\hline
\end{tabular}

Tablo 5 incelendiğinde üstbiliş eğitimi alan öğrencilerin seviye puanı ortalaması ile ( $\bar{X}=3.90)$ üstbiliş eğitimi almayan öğrencilerin puan ortalamaları $(\bar{X}=3.68)$ arasında anlamlı bir fark görülmüştür $(\mathrm{t}(306)=3.01, \mathrm{p}<.05)$. Bu durumda üstbiliş eğitiminin uzaktan eğitim öğrencilerinin biliş düzenlemesi seviyeleri üzerinde anlamlı bir etkisinin olduğu görülmüştür.

Öğrencilerin, biliş düzenlemesi seviyelerinin alt boyutları olan planlama, izleme, değerlendirme, hata ayıklama ve bilgiyi yönetme seviyelerinin farklılaşıp farklılaşmadığ 1 tespit edilmiştir. Bunun için bağımsız t-testi kullanılarak bulgular oluşturulmuştur. Elde edilen ortalamalar ve t-testi sonuçları Tablo 6'da gösterilmiştir. 
Tablo 6.

Uzaktan Ĕ̆itim Öğrencilerinin Planlama, İzleme, Değerlendirme, Hata Ayıklama ve Bilgiyi Yönetme Seviyeleri

\begin{tabular}{|c|c|c|c|c|c|}
\hline $\begin{array}{l}\text { Biliş } \\
\text { düzenleme } \\
\text { seviyesi }\end{array}$ & Durum & $\bar{X}$ & $\mathbf{S}$ & $\mathbf{t}$ & $\mathbf{p}$ \\
\hline \multirow{2}{*}{ Planlama } & & 3.89 & .74 & \multirow{2}{*}{3.65} & \multirow{2}{*}{.00} \\
\hline & Eğitimi almayan öğrenciler & 3.54 & .90 & & \\
\hline \multirow{2}{*}{ İzleme } & Eğitimi alan öğrenciler & 3.98 & .65 & \multirow{2}{*}{3.53} & \multirow{2}{*}{.00} \\
\hline & Eğitimi almayan öğrenciler & 3.69 & .75 & & \\
\hline \multirow{2}{*}{ Değerlendirme } & Eğitimi alan öğrenciler & 3.90 & .73 & \multirow{2}{*}{2.50} & \multirow{2}{*}{.01} \\
\hline & Eğitimi almayan öğrenciler & 3.67 & .83 & & \\
\hline \multirow{2}{*}{ Hata ayıklama } & Eğitimi alan öğrenciler & 3.98 & .66 & \multirow{2}{*}{2.19} & \multirow{2}{*}{.02} \\
\hline & Eğitimi almayan öğrenciler & 3.79 & .84 & & \\
\hline \multirow{2}{*}{$\begin{array}{l}\text { Bilgiyi } \\
\text { yönetme }\end{array}$} & Eğitimi alan öğrenciler & 3.80 & .65 & \multirow[b]{2}{*}{1.53} & \multirow[b]{2}{*}{.12} \\
\hline & Eğitimi almayan öğrenciler & 3.68 & .77 & & \\
\hline
\end{tabular}

Tablo 6 incelendiğinde üstbiliş eğitimi alan öğrencilerin planlamaya yönelik puan ortalaması ile $(\bar{X}=3.89)$ üstbiliş eğitimi almayan öğrencilerin seviye puanı ortalamaları ( $\bar{X}=3.54)$ arasında anlamlı bir fark görülmüştür $(\mathrm{t}(306)=3.65, \mathrm{p}<.05)$. İzleme seviyeleri arasında ise üstbiliş eğitimi alan öğrencilerin seviye puanı ortalaması ile ( $\bar{X}=3.98)$ üstbiliş eğitimi almayan öğrencilerin ortalamaları $(\bar{X}=3.69)$ arasında anlamlı bir fark görülmüştür $(\mathrm{t}(306)=3.53, \mathrm{p}<.05)$. Değerlendirme seviyeleri arasında üstbiliş eğitimi alan öğrencilerin seviye puanı ortalaması ile ( $\bar{X}=3.90)$ üstbiliş eğitimi almayan öğrencilerin ortalamaları $(\bar{X}=3.67)$ arasında anlamlı bir fark görülmüştür $(\mathrm{t}(306)=2.50, \mathrm{p}<.05)$. Hata ayıklama seviyeleri arasında üstbiliş eğitimi alan öğrencilerin seviye puanı ortalaması ile $(\bar{X}=3.98)$ üstbiliş eğitimi almayan öğrencilerin ortalamaları $(\bar{X}=3.79)$ arasında anlamlı bir fark görülmüştür $(\mathrm{t}(306)=2.19, \mathrm{p}<.05)$. Bilgiyi yönetme seviyeleri arasında üstbiliş eğitimi alan öğrencilerin seviye puanı ortalaması ile $(\bar{X}=3.80)$ üstbiliş eğitimi almayan öğrencilerin puan ortalamaları $(\bar{X}=3.68)$ arasında anlamlı bir fark görülmemiştir $(\mathrm{t}(306)=1.53, \mathrm{p}>.05)$. Bu durumda üstbiliş eğitiminin uzaktan eğitim öğrencilerinin planlama, izleme, değerlendirme, hata ayıklama seviyeleri üzerinde anlamlı bir etkisinin olduğu bilgiyi yönteme seviyeleri üzerinde anlamlı etkisinin olmadığı görülmüştür. 


\section{Tartışma, Sonuç ve Öneriler}

Üstbiliş eğitimi alan ve almayan uzaktan eğitim öğrencilerinin üstbilişel farkındalık seviyelerinin incelenmesi sonucunda üstbiliş eğitiminin uzaktan eğitim öğrencilerinin üstbiliş farkındalık seviyeleri üzerinde etkili olduğu görülmüştür. Bu sonuç üstbiliş eğitiminin öğrencilere aktarılmasının kendi öğrenme becerilerinin ve eğilimlerinin farkına varması ile açıklanabilir (Toney, 2000; Winne ve Hadwin 2008; Veenman 2011). Uzaktan eğitimde öğrenenler kendi öğrenmelerini kendilerine göre bağımsız bir şekilde gerçekleştirdiğinden ve bu ortamlarda kişiye özel bireysel öğrenme ortamları sunulduğundan üstbiliş eğitimi önemli rol oynamaktadır (Aydemir ve Karaman, 2017; Azevedo, 2005). Üstbiliş eğitimine uzaktan eğitim öğrencileri daha fazla ihtiyaç duymaktadır (Tok, Özgan ve Döş, 2010; Zahedi ve Dorrimanesh, 2008).

Üstbilişin bir alt kategorisi olan biliş bilgisi, bireyin kendi bilişsel süreçlerine yönelik ne, nasıl ve niçin bilgisini içermektedir. Üstbiliş eğitimi uzaktan eğitim öğrencilerinin biliş bilgisi farkındalık seviyesi üzerinde de etkili olmuştur. Üstbiliş eğitimi uzaktan eğitim öğrencilerinin biliş bilgisinin alt kategorileri olan prosedürel ve durumsal bilgi farkındalık seviyelerinde etkili olurken açıklayıcı bilgi farkındalık seviyesinde etkili olmamıştır. Verilen eğitim öğrencilerin ne bildiğine yönelik kendi sorgulaması üzerinde farkındalık oluşturmamıştır. Bu sonuç, öğrencilerin eğitim öncesinde ne bildiklerine yönelik farkındalıklarının olmasıyla açıklanabilir. Öğrenciler eğitim sayesinde daha çok nasıl ve niçin bildiğine yönelik kendini sorgulayarak farkındalık oluşturmuştur (Pehlivan 2012). Bu sonuç ise, öğrencilerin eğitim sayesinde bilişsel süreçleri, yetenekleri ve farkındalıkları hakkındaki nasıl ve niçin bilgisini sorgulamalarıyla açıklanabilir (Çalışkan ve Sünbül, 2011; Özsoy, 2007).

Üstbilişin bir diğer alt kategorisi olan biliş düzenlemesi ise bireyin bilişsel süreçlerini organize etmeye yönelik becerileri ve stratejileri içermektedir. Üstbiliş eğitimi uzaktan eğitim öğrencilerinin biliş düzenlemesi farkındalık seviyesi üzerinde de etkili olmuştur. Üstbiliş eğitiminde öğrencilerin kendi zihinsel süreçlerine ve bilgiye nasıl ulaştıklarına yönelik yaptıkları eylemleri düşünmeleriyle (DarlingHammond vd., 2003) açıklanabilir. Bilgiyi yönetme boyutu daha çok organize etme, detaylandırma ve özetleme becerilerini içermektedir (Schraw ve Dennison, 1994). Bu boyutta farklılık çıkmaması ise uzaktan eğitim öğrencilerinin bu becerilerde yetkin olması ile açıklanabilir (Dabbagh, 2007).

Çalışmadan elde edilen sonuçlar ışı̆̆ında aşağıdaki öneriler yapılabilir.

$\checkmark$ Uzaktan eğitimde, üstbiliş eğitimi ile uzaktan öğrenenlerin ihtiyaçları giderilerek kendi öğrenme becerilerinin ve eğilimlerinin farkında olması sağlanabilir.

$\checkmark$ Uzaktan eğitimde, üstbiliş eğitimi ile uzaktan öğrenenlerin nasıl ve niçin öğrendiğine yönelik kendilerini sorgulayıp öğrenimlerini düzenlemesi sağlanabilir. 
$\checkmark$ Uzaktan eğitimde, üstbiliş eğitimi ile uzaktan öğrenenlerin planlama, izleme, değerlendirme ve düzenleme becerilerine yönelik farkındalık oluşturması sağlanabilir.

$\checkmark$ Gelecekteki çalışmalar uzaktan eğitimde etkinlikler aracılığıyla verilen üstbiliş eğitiminin üstbilişsel farkındalık seviyesi ve boyutlarına yönelik etkisi olup olmadığını inceleyecek şekilde yapılabilir.

$\checkmark$ Uzaktan öğrenenlerin üstbilişsel farkındalık seviyelerine yönelik farklılıkların neden kaynaklandığını derinlemesine inceleyen çalışmalar yapılabilir.

\section{Kaynakça}

Akın, A., Abacı R. \& Çetin, B. (2007). Bilişötesi Farkındalık Envanteri'nin Türkçe formunun geçerlik ve güvenirlik çalışması. Kuram ve Uygulamada Eğitim Bilimleri, 7(2), 655680 .

Aydemir, M. (2014). Uzaktan eğitimde üstbilişsel etkinliklerin öğrencilerin ders çalışma süreçleri ve üstbilişsel becerileri açısından incelenmesi (Yayınlanmış doktora tezi). Atatürk Üniversitesi, Erzurum.

Aydemir, M. \& Karaman, S. (2017). Üstbilişsel etkinliklerin uzaktan eğitim öğrencilerinin üstbilişsel seviyeleri ve ders çalışma süreçleri açısından incelenmesi. Eğitim Teknolojisi Kuram ve Uygulama, 7(2), 18-40.

Azevedo, R. (2005). Computer environments as metacognitive tools for enhancing learning. Educational Psychologist, 40(4), 193-197.

Bağçeci, B., Döş, B. \& Sarıca, R. (2011). İlköğretim öğrencilerinin üstbilişsel farkındalık düzeyleri ile akademik başarısı arasındaki ilişsinin incelenmesi. Mustafa Kemal Üniversitesi Sosyal Bilimler Enstitüsü Dergisi, 8(16), 551-566.

Blakey, E. \& Spence, S. (1990). Developing metacognition. ERIC Digest. Retrieved 19 March, 2018, from https://eric.ed.gov/?id=ED327218

Brown A.L. (1987). Metacognition, executive control, self-regulation, and other more mysterious mechanisms, (Ed. F. E. Weinert \& R. H. Kluwe). Metacognition, motivation, and understanding, (65-116). Hillsdale Lawrence Erlbaum Associates, New Jersey.

Büyüköztürk, Ş., K1lıç Çakmak, E., Akgün, Ö.E., Karadeniz, Ş. \& Demirel, F. (2008). Bilimsel araştırma yöntemleri. Ankara: Pegem Yayınları.

Curwen, M.S., Miller, R.G., White-Smith, K.A. \& Calfee, R.C. (2010). Increasing teachers' metacognition develops students' higher learning during content area literacy instruction: Findings from the read-write cycle project. Issues in Teacher Education, 19(2), 127-151.

Çalışkan, M. \& Sünbül, A.M. (2011). Öğrenme stratejileri öğretiminin yürütücü biliş bilgisine, yürütücü biliş becerilerini kullanmaya ve başarıya etkisi (ilköğretim 6. sınıf Türkçe dersi örneği). Kuram ve Uygulamada Eğitim Bilimleri, 11(1), 133-153. 
Dabbagh, N. (2007). The online learner: Characteristics and pedagogical implications. Contemporary Issues in Technology and Teacher Education, 7(3), 217-226.

Darling-Hammond, L., Austin, K., Cheung, M. \& Martin, D. (2003). Thinking about thinking: Metacognition. Stanford: Stanford University School of Education.

Flavell, J.H. (1979). Metacognition and cognitive monitoring: A new area of cognitivedevelopmental inquiry. American Psychologist, 34(10), 906-911.

Fraenkel, J.R. \& Wallen, N.E. (2006). How to design and evaluate research in education (6th Ed.). New York: NY McGraw-Hill.

Gama, C. (2001). Investigating the effects of training in metacognition in an interactive learning environment: Design of an empirical study. In B. Zayas and C. Gama (Eds.). Proceedings of the 5th Human Centred Technology Postgraduate Workshop. Brighton, UK: University of Sussex-Cognitive Science Research Paper 538.

Hartman, H.P. (1998). Metacognition in teaching and learning: An introduction. Instructional Science-International Journal of Learning and Cognition, 26, 1-3.

Howard, B.C., McGee, S., Hong, N.S. \& Shia, R. (2000, April). The influence of metacognitive self-regulation and ability levels on problem solving. Paper presented at the Annual Meeting of the American Educational Research Association (New Orleans, LA, April 24-28, 2000).

Joseph, N. (2009). Metacognition needed: Teaching middle and high school students to develop strategic learning skills. Preventing School Failure: Alternative Education for Children and Youth, 54(2), 99-103.

Kana, F. (2015). Türkçe öğretmeni adaylarının üstbiliş farkındalık düzeyleri. Akademik Sosyal Araştırmalar Dergisi, 3(17), 66-81.

Mayer, R.E. (1987), Educational psychology: A cognitive approach. USA: Little-Brown and Company Ltd.

Mayer, R.E. (2009). Multimedia learning (2nd Ed.). Newyork: Cambridge University Press.

Özsoy, G. (2007). İlköğretim beşinci sınıf düzeyinde üstbiliş stratejileri öğretiminin, problem çözme başarısına etkisi (Yayınlanmış doktora tezi). Gazi Üniversitesi, Ankara.

Öztürk, N. (2016). An analysis of pre-service elementary teachers' understanding of metacognition and pedagogies of metacognition. Journal of Teacher Education and Educators, 5(1), 47- 68.

Papaleontiou-Louca, E. (2003). The concept and instruction of metacognition. Teacher Development, 7(1), 9-30.

Pehlivan, F. (2012). İlköğretim beşinci sınıf matematik dersinde üstbiliş stratejileri kullanımının ögrencilerin başarı ve tutumlarına etkisi (Yüksek lisans tezi). Niğde Üniversitesi, Kırşehir.

Pintrich, P.R., Wolters, C.A. \& Baxter, G.P. (2000). Assessing metacognition and selfregulated learning. In G. Schraw and J. C. Impara (Eds.), Issues in the measurement of metacognition (43-99). Lincoln: Buros Institute of Mental Measurements. 
Schraw, G. \& Dennison, R.S. (1994). Assessing metacognitive awareness. Contemporary Educational Psychology, 19, 460-475.

Schraw, G., Wise, S.L. \& Roos, L.L. (2000). Metacognition and computer-based testing. In G. Schraw \& J.C. Impara (Eds.), Issues in the measurement of metacognition (223-262). Lincoln: Buros Institute of Mental Measurements.

Singh, O.B. (2009). Development and validation of a web-based module to teach metacognitive learning strategies to students in higher education (Published doctoral dissertations). University of South Florida, U.S.A.

Thomas, G.P. \& Mcrobbie, C.J. (2001). Using a metaphor for learning to improve students' metacognition in the chemistry classroom. Journal of Research in Science Teaching, $38(2), 222-259$.

Tok, H., Özgan, H. \& Döş, B. (2010). Assessing metacognitive awareness and learning strategies as positıve predictors for success in a distance learning class. Mustafa Kemal Üniversitesi Sosyal Bilimler Enstitüsü Dergisi, 7(14), 123-134.

Toney, R.J. (2000). An investigation of learner control and metacognition using a web-based training program (Unpublished doctoral dissertation). Michigan State University, East Lansing MI.

Winne, P.H. \& Hadwin, A.F. (2008). The weave of motivation and self-regulated learning. In D. H. Schunk \& B. J. Zimmerman (Eds.), Motivation and self-regulated learning. Theory, research, and applications (pp. 297-314). Mahwah, NJ, US: Lawrence Erlbaum Associates Publishers.

Veenman, M.V.J. (2011). Learning to self-monitor and self-regulate. In R. Mayer and P. Alexander (Eds.), Handbook of research on learning and instruction (197-218). New York: Routledge.

Veenman, M.V.J., Elshout, J.J. \& Busato, V.V. (1994) Metacognitive mediation in learning with computer-based simulations.Computers in Human Behavior, 10, 93-106.

Vovides, Y. (2005). Investigating learning from hypermedia via the implementation of a computer-based metacognition training regimen and a hypermedia program (Published doctoral dissertation). IA: The University of Iowa, Iowa City.

Zahedi, K. \& Dorrimanesh, P. (2008). Metacognitive learning strategies and academic success of TEFL M.A. students in distance education. International Journal of Criminology and Sociological Theory, 1(2), 161-176.

\section{Extended Abstract}

Distance education mainly involves learning environments and processes suitable for individual learning. The learners realize their own learning in these environments. Individuals have metacognition are also able to aware, control and organize their own learning processes (Joseph, 2009). In this respect, metacognition plays an important role in distance education (Azevedo, 2005). Distance education students need metacognition training (Tok, Özgan and Döş, 2010; Zahedi and Dorrimanesh, 2008). 
Therefore, attention should be paid to the need to include metacognition training in these settings (Aydemir; 2014).

The aim of this study was to examine the metacognitive awareness levels of distance education students who receive and do not receive the metacognition training. For this purpose, the following research questions were sought.

1. Is there a significant difference in the metacognitive awareness level of distance education students with and without metacognition training?

2. Is there a significant difference in the knowledge of cognition level of distance education students with and without metacognition training?

a. Is there a significant difference in the declarative knowledge, procedural knowledge and conditional knowledge level of distance education students with and without metacognition training?

3. Is there a significant difference in the regulation knowledge level of distance education students with and without metacognition training?

a. Is there a significant difference in the planning, information, management strategies, monitoring, debugging strategies and evaluation level of distance education students with and without metacognition training?

Static group comparison design was used to determine metacognition levels of distance education students who did or did not receive metacognition teaching. The final measurements of the two groups are compared at static group comparison design. While application is done in a group, the application is not done in another group. Assignments to groups are not random, there are ready groups (Büyüköztürk, Çakmak, Akgün, Karadeniz and Demirel, 2008). In this study, there are two groups with and without metacognition training. At the end of the process, the scale scores of these two groups were compared.

The sample of this research consists of 307 first grade students of Ataturk University Open Education Faculty. The sample has been selected from easily accessible units due to the preference of students using and not using educational material about metacognition training. The main purpose in this method is to prevent time and job loss (Büyüköztürk, at all., 2008; Fraenkel and Wallen, 2006). The majority of the students are women ( $\%$ 64.82).

The majority of students are in the 20-30 age range ( $\% 38.44$ ). This is followed by the $30-40$ age range ( $\% 25.73$ ), the $40-50$ age range ( $\% 15.64$ ), the $50-60$ age range ( $\%$ 10.42) and before 20 years ( $\%$ 9.72) respectively.

Metacognition, characteristics and importance of metacognition, metacognitive components, metacognitive strategies and examples are explained through multimedia elements in the educational software at Learning Management System (LMS). In the 
software, there are 4 educational videos which consist of 2-3 minutes in total, concept network and evaluation questions. Multimedia design principles are used in software about metacognition training (Mayer, 2009). The software has six parts. In the first part, the students learn the learning outcomes that will be gained after the use of this educational software. In the second part, information about metacognition is given. In the third part, metacognitive strategies are explained. In the fourth part, metacognitive activities are explained. In the fifth part, there are evaluation questions. In the sixth part, information is given about the use of educational software.

In this study, "Metacognitive Awareness Inventory (MAI)" developed by Schraw and Dennison (1994) and prepared Turkish version by Akın, Abacı and Çetin (2007) was used to examine the effect of metacognition teaching on metacognitive levels of distance education students. The scale was presented to students at LMS. The students received education completed the scale after using metacognition educational software. The students not received education completed the scale any time. Data were analyzed by independent t-test.

There was a significant difference in metacognitive awareness levels between students who have metacognition teaching and don't receive metacognition teaching. This result can be explained by the fact that the transfer of metacognition training to the students becomes aware of their own learning skills and tendencies (Toney, 2000; Winne and Hadwin 2008; Veenman 2011). Metacognition training plays an important role in distance education as learners perform their own learning independently and individualized learning environments are provided (Azevedo, 2005). Distance education students need more education about metacognition (Tok, Özgan and Döş, 2010; Zahedi and Dorrimanesh, 2008). This need can be eliminated by metacognition training at distance education. 